\title{
VERSKI FUNDAMENTALIZAM
}

\section{RELIGIOUS FUNDAMENTALISM}

\author{
Boris Bursać \\ Gradska opština Čukarica, Beograd, Srbija
}

CMESTE

JEL Category: Z12

\begin{abstract}
Apstrakt
Jedan od najčešće korišćenih termina današnjice svakako je fundamentalizam, iz kojeg se izvodi termin verski odnosno religijski da bi na kraju došli do danas najfrekventnijeg a to je islamski fundamentalizam. Fundamentalizam kao termin potiče od latinske reči "fundamentum" i u prevodu znači osnova. Ovaj pojam možemo definisati kao stav gde se odredjena načela smatraju suštinskim odnosno temeljnim istinama $i$ imaju nepromenljiv to jest neprikosnoven autoritet. Ako govorimo o fundamentalističkim pokretima, autorka Karen Armstrong ih definiše kao „poražene oblike duhovnosti koji su nastali kao odgovor na uočene krize". Te krize se javljaju upravo unutar religija a tu podrazumevamo: hrišćanstvo, judaizam, islam gde se ovaj termin koristi za naj konzervativnija krila unutar tih religija. Cilj ovog rada je da čitaoca bliže upozna sa ovim izuzetno aktuelnim i složenim fenomenom i ukaže na njegovu svestranost odnosno prisutnost u svim segmentima čovekovog bivstvovanja počev od religije, politike, pa sve do filozofije.
\end{abstract}

Ključne reči: fundamentalizam, religija, verski identitet, ekstremizam, konzervativizam

\begin{abstract}
One of the most frequently used today's term is certainly the fundamentalism, from which the term religious fundamentalism comes out to eventually reach the most frequent, and that is Islamic fundamentalism. Fundamentalism as a term derives from the Latin word "fundamentum" and in translation means the basis. This term can be defined as a position where certain principles are considered essential or fundamental truthsand they have an unchangeable or inviolable authority. If we talk about fundamentalist movements, author Karen Armstrong defines them as "defeated forms of spirituality that have emerged in response to the perceived crises." These crises occur within religions, and this includes Christianity, Judaism, Islam where this term is used for the most conservative wings within these religions. The aim of this research is to introduce the reader with this extremely topical and complex phenomenon and pointing at its versatility, or presence in all segments of man's being, starting from religion, politics, and philosophy.
\end{abstract}

Keywords: fundamentalism, religion, religious identity, extremism, conservatism

Adresa autora:

Boris Bursać

夆”boris.bursac89@gmail.com

\section{UVOD}

Možemo sa sigurnošću reći da je religija ništa drugo do jedan pre svega višedimenzionalan 
fenomen koji je izrazito kompleksan, jer smo svedoci da svaka religija tvrdi i proglašava svoje verovanje za jedino pravo i istinsko. Stoga svaka religija ima za cilj širenje vere i zaštitu verskog identiteta pa se refleksno javlja odbranbeni stav činioca jedne religije. $U$ takvim momentima pojedinac ili grupa sve što radi, radi u ime Boga ili po Božijem naređenju odnosno radi ostvarenja Božijeg cilja te takve grupe ili pojedinci često pribegavaju nasilju, ekstremizmu u čijoj je osnovi verski fundamentalizam. Kad govorimo o fundamentalizmu moramo izrazito obratiti pažnju na njegovu svestranost, odnosno prisutnost $u$ svim segmentima čovekovog bivstvovanja počev od religije, politike, filozofije. $U$ religiji fundamentalizam se najčešće vezuje za islam odnosno na Iran pod Homeinijem a kasnije i na mnoge druge islamske zemlje. U politici odnosi se na nosioce nekih političkih ubeđenja naravno poniklih iz svojevrsnih alternativnih pokreta koji zastupaju i teže ostvarenju svojih radikalnih zahteva, dok u filozofiji pamtimo Hansa Alberta koji je fundamentalističkim označio sve pravce koji pre svega polaze od sigurne ali $i$ nedvosmislene spoznaje a kao primer uzeo je marksističku argumentaciju i hiršćansku teologiju. Sam izraz fundamentalizam prošao je kroz nekoliko etapa razvoja počev od američkog protestantizma koji je suštinski i tvorac ovog fenomena pa sve do nečega što se danas naziva "sveti teror", cilj ovog eseja biće upravo da objasni ove etape i pojam fundamentalizam kao fenomen. U nauci postoji mnoštvo studija koje se bave upravo fundamentalizmom i fundamentalističkim pokretima ali ako posmatramo ovaj fenomen sa jednog metodološkog aspekta sve ono što je obeleženo ili definisano ovim terminom nalazi se u nekoj pionirskoj fazi. Stoga ovaj termin jeste na početku bio vezivan isključivo za veru, teologiju, adekvatno tumačenje verskog teksta, dok danas fundamentalizam doživljava svoju punu ekspanziju i jednostavno se nameće potreba za njegovim objašnjenjem. Istina je da ovaj termin iskočio u prvi plan akademske zajednice i šire javnosti najviše zahvaljujući multikulturalnosti i transnacionalizmu gde ljudi i same ideje svetlosnom brzinom obilaze planetu i nalaze svoje mesto pod suncem, tako je i fundamentalizam bio on verski ili ne dostigao svoj vrhunac i obeležio jednu epohu.

\section{KRATAK OSVRT NA ISTORIJU}

Da bi se upoznali sa osnovama fundamentalizma tačnije verskog fundamentalizma moramo se osloniti na istorijski kontekst koji je jako bitan za ovu tematiku. Koren fundamentalizma leži u američkom protestantizmu odnosno u takozvanom militantnom evangelizmu dvadesetih godina prošlog veka, preciznije u raspravi koja se razvila između fundamentalista i naravno modernista tog vremena. E sad kad ovako postavimo stvari dolazimo do pitanja da li je svaki fundamentalizam po automatizmu verski, jer se ovaj prvi vezuje za religiju? Svakako da ne. Problem koji se tu javlja je vrlo jasan, fundamentalizmi se mešaju, često politički fundamentalizam deluje kao verski ali u svojoj biti on to nije, dok sa druge strane imamo opciju i da verski fundamentalizam vrlo često teži moći i uticaju pre svega u politici ali i u državi te stoga uvek moramo težiti distinkciji - šta je to versko, a šta političko u ovoj tematici. Kad govorimo o verskom odnosno religijskom fundamentalizmu prvo što nam padne na pamet je islam, te se zbog toga moram složiti sa Prof. Draganom Simeunovićem koji kaže da pripisivanje islamu statusa jedine velike religije koja rađa fundamentalizam, ekstremizam i nasilje je nepravedno. (Simeunović, 2009) lako se fundamentalizam s pravom najčešće spominje $u$ vezi sa islamom, nema ni jedne velike religije, uključujući i vrlo tolerantni budizam koju nije obeležio njen fundamentalizam, a mnoge od njih i ekstremizam. (Brasher, 2001)Kad govorimo o fundamentalizmu ponekad je izuzetno teško odvojiti ga od prvobitnog značenja koje je imao pre svega u protestantizmu. Protestantski fundamentalisti su u katolicizmu videli ono najcrnje odnosno svojevrsno izvrtanje hrišćanskog učenja, i vrlo mali broj njih, upotrebiće izraz katolički fundamentalizam, s obzirom da je ova konstrukcija za njih apsurdna radije će se koristiti terminom, katolički konzervativizam te će se i konzervativizam katolika porediti sa ostalim oblicima konzervativizma bilo onim militantnim ili umerenim. (Munson, 2003). Nego da se vratimo $\mathrm{mi}$ verskom fundamentalizmu i njegovim protestanskim korenima. Dakle kao što smo ustanovili fundamentalizam je verski pokret odnosno ideologija koja se pojavila u imigrantskoj Americi u XIX veku. Naime ovaj izraz je prvi put 
upotrebio pastor Kurtis Li Lavs (Curtis Lee Laws) i to u Glasniku baptističke kongregacije prilikom pozitivnog samopredstavljanja, gde pastor Lavs opisuje borbu za osnovna načela predstavljena u dvanaest pamfleta nazvanih Fundamenti vere koji su štampani u periodu između 1915. i 1920. godine a koji su se konkretno usredsredili na određeni broj naravno hrišćanskih dogmi, sa jasnom namerom branjenja istih od konstantnih napada modernih i svakako liberalnih teologa. (Sandeen, 1967). Te dogme su se konkretno odnosile na nepogrešivost Svetog Pisma, devičansko rođenje Gospoda Isusa Hrista, vaskrsenje mrtvih, božanstvo Gospoda Isusa Hrista, drugi Hristov dolazak itd. Ono što je jako bitno za fundamentalizam koji se razvijao $u$ Americi svakako je i to da njemu nisu pripadale samo crkve već i važni pokreti kao što je Hrišćanski studentski pokret ili CVJM. Ovaj pokret je imao za cilj verovali ili ne spasenje duša i to kroz evangelizaciju i docnije naravno preobraćenje. Ono što je evangeliste karakterisalo u tom periodu svakako je optimizam i to onaj optimizam napretka, oni su željno isčekivali hiljadugodišnje carstvo Apokalipse ali ubrzo su se okrenuli borbi protiv modernog sveta. Ono na čemu se zasnivaju fundamentalisti u SAD i po čemu se distanciraju od moderne i kritičke teologije savremenog sveta naziva se,, The five points of fundamentalism" $i$ to su (Kincler, 2002):

- Apsolutna autentičnost Svetog pisma

- Partenogeneza

- Žrtva ispaštanja

- Telesno uskrsnuće

- Hristov povratak radi uspostavljanja hiljadugodišnjeg carstva do poslednjeg suda.

Naravno na osnovu ove podele možemo zaključiti da sve navedene tačke verovatno nemaju istu težinu ali na osnovu njihovog redosleda predpostavljamo i utvrđujemo njihovu snagu. $U$ suštini ovaj fundamentalizam, kako navodi Kincler u svojoj knjizi „Verski fundamentalizam: hrišćanstvo, judaizam, islam" se u načelu okreće:

1. Protiv relativizacije autoriteta Biblije na osnovu istorijsko - kritičkih istraživanja.

2. Protiv svođenja Isusa Hrista na čisto ljudski nivo

3. Protiv darvinističkog osporavnja nastanka čoveka kroz poseban božanski stvaralački akt
4. A zalaže se za spas duše putem najave skorog povratka Isusa Hrista koji će uspostaviti svoju vlast na zemlji.

Na osnovu gore navedenog možemo zaključiti da je fundamentalizam unutar američkog protestantizma istupao protiv bilo kakvog biblijskog kriticizma, protiv Darvinove teorije evolucije, ničeanske filozofije ali da se sa druge strane zalagao isključivo za biblijski literalizam, patrijahalni moral koji sa sobom vuče autoritet, $i$ samokontrolu uz koju ide kontrola svih ali podvlačim svih društvenih poroka. Fundamentalizam u SAD je bio u stalnim usponima i padovima da bi svoj vrhunac dostigao u 1984. Godini zahvaljujući Džeriju Falvelu (Jerry Falwell) koji je spojio fundamentalizam sa politikom kroz otvoreni savez fundamentalista i neokonzervativnih republikanaca. Šlag na torti bio je izbor Ronalda Regana za predsednika SAD-a gde su analitičari tih izbora jasno stavli do znanja da je upravo za njegov izbor zaslužan fundamentalistički pokret, odnosno njegovi duhovnici i propovednici jer su pokrenuli onaj konzervativni desni protestanski blok. Dva pokreta tu iskaču u prvi plani i svoje ideje baziraju na fundamentalizmu a to su svakako Moral Majority i novoformirani New Right. U tom momentu fundamentalizam u SAD-u prestaje da bude verski i postaje politički. Kad govorimo o funadamentalizmu u Evropi on svakako okuplja milione pripadnika ali različitih crkava unutar Hrišćanstva tu spadaju svakako: kalvinistička, baptistička, pijetistička i sve one sebe smatraju fundamentalističkim. Uticaj fundamentalizma na Evropu je svakako ograničen ali svoj najveći uticaj i delovanje ostvaruje preko protestantskoevangelističkih krugova. Veliki uticaj fundamentalizam ima u Nemačkoj stoga logično je da pomenemo neke od intersantnih fundamentalističkih pojava upravo u ovoj evropskoj državi a to su (Kincler, 2002):

1. "Uzbuna oko Biblije" - Gerhard Brigman knjiga koja govori o opasnosti moderne nauke o Bibliji

2. Pokret "Samo ovo Jevađelje“ formirano 1966. godine

3. Privremeni bojkot nemačkog evangelističkog sabora od strane Konferencije zajednica veroispovedajućih Nemačke evangelističke crkve 
4. Fundamentalističko prosvetno društvo „Reč i znanje"

5. Formiranje „Slobodne evangelističkoteološke akademije" (FETA) u Bazelu.

Ono što spaja nemački evangelističi protestantizam i fundamentalizam su svakako fundamentalističko shvatanje Biblije ali i altrenative uobičajenom sistemu obrazovanja kroz formiranje veroispovednih škola, fakulteta i akademija1, rad u oblasti izdavaštva i medija sa ciljem brzog pridobijanja sledbenika - poznate su izdavačka kuća Hensler, informativna služba Idea. $\mathrm{E}$ sad kad smo to ustanovili moramo i iskristalisati problematiku vezanu za mešanje pojmova. Naime fundamentalizam odnosno pojam fundamentalistički se konstantno izjednačava sa pojmovima evangelistički, pijetistički ili konzervativni.

Pojam evangelistički vezujemo za XVI vek u Engleskoj odnosno za sledbenike protestantske reformacije u oviru državne Anglikanske crkve, kasnije je ovaj termin potisnut pojmom protestantski. Koreni evangelizma se u suštini nalaze $u$ pijetizmu odatle potiče upravo ono naglašavanje Biblije $i$ lične vere $u$ Isusa Hrista. Ono što spaja pijetiste, evangeliste i fundamentaliste upravo je esencijalni značaj Svetog pisma, lična pobožnost i borba protiv bilo kakvih moderno-liberalnih teoloških primesa. Pomenuli smo sve ove crkve unutar hrišćanstva ali nismo katolicizam te stoga moramo posvetiti pažnju i ovom pravcu. U katoličkim krugovima i to je ono što je odlika ovog pravaca u hrišćanstvu se dugo krilo i nije se pričalo o fundamentalizmu dok se danas to radi vrlo otvoreno. Nekad su se fundamentalističke ideje prikrivale pojmovima kao što su „antimodernizam“ ili „integralizam“ i taj period katoličke crkve je ostao pod velom tajni jer ga odlikuje otvorena borba sa modernizmom koji ima jasne obrise fundamentalizma, te ćemo se osvrnuti na taj period $u$ daljem delu teksta. Katoličku crkvu su u tom periodu zadesile dve krize odnosno prva i druga modernistička kriza. Prva modernistička kriza dešavala se za vreme

${ }^{1} U$ Saveznoj republici Nemačkoj 1991. godine formirano je oko 29 evangelističkih privatnih škola a kasnije i Slobodna teološka akademija u Gisenu. pontifikata Pija IX-og koji je obeležila borba protiv modernih i tradicionalnih crkvenih stavova. U ovom periodu papa Pije IX je doneo i sproveo takozvani Silabus. $U$ njemu su precizno navedene sve zablude tog vremena tačnije njih osamnaest. U Silabusu pape Pija IX žigosane su određene ideologije kao što su liberalizam i komunizam, loši društveni poretci kao što je moderna demokratija itd. Dakle u ovoj prvoj krizi koja je zadesila Katoličku crkvu akcenat je stavljen na društveno, političko i duhovnoistorijsko pravo Katoličke crkve u modernom svetu, pri čemu se Katolička crkva nije ustezala da upotrebi sredstva prinude kada je to bilo potrebno. U Nemačkoj je zbog ove krize došlo do kulturne borbe te je došlo do stvaranja katoličkog socijalnog miljea u svim oblastima društva počev od obrazovanja, kulture do načina življenja. Druga modernistička kriza desila se za vreme pontifikata Pija $X$ a svoju snagu crpi iz dva dokumenta Lamentabili2 i Poslanica Pija X. Oba dokumenta potvrđuju integralistički pravac Katoličke crkve, ova dva dokumenta u istoriji su ostala poznata pod nazivom Novi Silabus i činilo in je 65 novih zabluda. Suštinski najviše pažnje posvećeno je sukobu sa istorijsko - kritičkom metodom u egzegezi i naravno istoriji i dogmi. Ovaj proces trajao je decenijama i možemo ga opisati kao, rat papirima“. Fundamentalizam u ovoj drugoj krizi se ogleda u sporu oko Biblije i naučne teologije, a fundamentalističke opasnosti pojavljuju se onda kada se naruši ravnoteža jedne od sukobljenih strana u Katoličkoj crkvi najčešće kada se naruši primat doktrinranog saveta. Fundamentalističke pojave u Katoličkoj crkvi se oblikuju u više ili manje militantne frakcije unutar same crkve, te frakcije se nisu odvojile od jedinstva Crkve osim ako ih sama Crkva nije odvojila poput šizmatika okupljenih oko nadbiskupa Marsela Lefevra ${ }^{3}$ (Marcel Lefebvre) ili su u nekom momentu upozoreni da se drže svojih okvira kao što je slučaj sa grupom Opus Angelorum. Najpoznatije fundamentalističke i miltantne grupe unutar Katoličke crkve su (Sandeen, 1967):

\footnotetext{
${ }^{2}$ Dekret svetog oficijuma

${ }^{3}$ Zastupnici rigoroznog tradicionalizma unutar Katoličke crkve koji traže vraćanje na latinsku tridentsku liturgiju i odvraćanje od „zabluda“, Drugog vatikanskog sabora.
} 
1. Tradicionalisti: okupljeni oko nadbiskupa Marsela Lefevra koji su se posle njegove ekskomunikacije podelili na: Bratstvo sv. Petra - nešizmatici sedište im je u Vigracbadu u Augzburškoj biskupiji imaju oko 46 sveštenika, dva đakona i 95 iskušenika. Imaju svoje ogranke u Štutgartu i Salcburgu i svoje časopise „Preokret“ i „Informativni list bratstva sv. Petra“.

2. Omladina Hrista kralja: - podmladak bratsva sv. Petra.

3. Opus Angelorum: - niz svešteničkih bratstava $\mathrm{O}$ svetom krstu i svetovnih bratstava kao što je Anđeo čuvar.

4. Opus Dei: jedna od najtajnijih i najrigoroznijih fundamentalističkih grupacija unutar Katoličke crkve, karakteriše in rigiorozan unutrašnji život (bič i pojas poklanjanja), indoktrinacija omladine, sektaška propaganda, umešanost članova u finansijske skandale

5. Pro Missa Tridentina: udruženje svetovnjaka koji se zalaže za liturgiju na latinskom

6. Pokret za papu i crkvu: osnovan je 1969. godine okuplja čitav niz grupacija iz Austrije i Nemačke poput Pro Occident, Vernost crkvi, Sveštenici iz Linca, Sveštenici iz Kelna. Pokret ima svoje časopise poput Stene i Trenta Giorni (Trideset dana).

7. Pokret Una-Voce: osnovan je 1964. godine koji finansira Una Voce Korespodenciju

8. Katoličko izviđačko društvo Evrope: ili KPE sa svojim osnivačem Andrasom Henišem spada u najkotraverznije grupacije unutar Katoličke crkve.

9. Društvo Isusovih i Marijinih sluga: deo je KPE-a i ima svoj časopis „Marijini izviđači“.

10. Udruženi apostolat u Marijinom duhu: poznat kao VAM, okuplja mnoge grupacije, pokrete i pojedince kao što su Katolička verska liga, Pokret za život, Akcija Fatima 77, Međugorje - Nemačka, Marijin sveštenički pokret (MPD), Omladina 2000, takođe VAM raspolaže sa svojim izdavčkim preduzećem „Maria aktuell“ i svojom radio stanicom „Radio Maria“.

Ove frakcije ili grupacije koriste se sličnim ili istim akcijama koje se ogledaju u otvorenima napadima na neistomišljenike ali $\mathrm{i}$ biskupe $\mathrm{i}$ papstvo ukoliko se ne odgovori na njihova upozorenja koja se vezuju uglavnom na loše stanje u Crkvi.

\section{FUNDEMENTALIZAM U JUDAIZMU}

Za judaizam temelj svega je Tora, u suštini ona predstavlja jevrejsku Bibliju koja sadrži tradicionalne jevrejske zakone kojih bi svaki pravoverni jevrej trebao da se pridržava. Sa druge strane pored Tore postoji i Talmud koji pored verskih tekstova sadrži i tekstove vezane za pravo, filozofiju, legende, bajke, zbirke rasprava viđenijih rabina o jevrejskoj etici, pravu, običajima i naravno istoriji. Talmud se sastoji iz dva dela Mišnah koji predstavlja pismeni pregled usmenog prava i Gemara koji predstavlja raspravu o Mišnah. Zato u judaimzmu postoji krilatica da je jedna pisana Tora - Biblija i jedna usmena Tora - Talmud. E sad postoje dva izdanja Talmuda jedan iz Jerusalima a jedan iz Vavilona poznatiji kao Babli - razlika se ogleda u tome da je ovaj drugi obimniji. Tora ima veliki značaj za jevrejski narod jer je ona upravo dar od Boga i mimo nje ništa ne postoji jer obuhvata sve aspekte ljudskog života te ju je nemoguće odvojiti od individualne, društvene ili državne sfere. Takođe moramo napomenuti da nema svako pravo da tumači Toru otud potreba za rabinima i otuda rabinska tradicija crpi svoju snagu i postaje sastavni deo Tore objavljene na Sinaju. Fundamentalizam u judaizmu vreba upravo iz rabinske tradicije odnosno iz tumačenja Tore jer su mnogi rabini tumačili Toru na razne načine ponekad pomalo različito ali ponekad i totalno protivurečno. Upravo tu leži izvor fundamentalizma $u$ judaizmu dakle $u$ različitom tumačenju verskih zakona gde postoji konstantna borba između ortodoksnog, reformatorskog i konzervativnog krila judaizma. Izvor opasnosti je u nepopustljivosti ovih krila odnosno grupa unutar judaizma koji više ne teže raspravama 0 osnovama judaizma već žele svoje stavove da nametnu kao jedine odnosno važeće za sve. Dakle ključni problem je u radikalizaciji verskih zakona odnosno u namerama pojedinih krila da sve oblasti života prožmu i baziraju na usmenoj i pismenoj Tori i to je upravo ta ultra ortodoksna zamisao koja budi fundamentalizam u ovoj religiji . Ova zamisao je obeležila Izrael i postala je i ostala pokretačka snaga ortodoksnih grupacija u ovoj državi. Jedna od najpoznatijih grupacija svakako je Agudat Jisrael koja se bori protiv reformističkog judaizma a zalaže se za striktno tradicionalne vrednost u judaizmu. Dokaz njihove 
moći i uticaja je to da je i prvi predsednik, Izrela Devid ben Gurion upravo savet i pomoć oko budućeg uređenja države tražio upravo od ove grupacije. On je zajedno sa „Agudat Jisrael“ uredio odnose između ortodoksije i politike i proklamovao dokument "Status kvo" kojim se uređuje sledeće:(Kincler, 2002)

1. Šabat se proglašava neradnim danom na nivou države

2. Verski regulisan način ishrane (kašrut) u svim državnim kuhinjama

3. Rabinski sudovi imaju jedini jurisdikciju nad sklapanjem i razvodom braka

4. Mora biti priznato obrazovnje verskih grupa

Ove ortodoksne grupacije su bile na vrhuncu moći 1977. godine kada su na čelu sa Agudat Jisrael srušili Izraelsku partiju rada i postavili Menahema Begina iz Likud bloka na funkciju premijera Izraela, za uzvrat tražili su pooštravanja u oblasti verskih zakona. Neki od najpoznatijih zakona su: da brak između dve osobe različite veroispovesti u Izraelu nije moguć ukoliko neko od njih ne promeni veru jer ne postoje svetovne istitucije za sklapanje braka, dobijanje izraelskog državljanstva podleže ortodoksnoj kontroli gde se "jevrejstvo“ državljanina strogo prati i kontroliše, autopsija i transplatacija se gotovo u potpunosti onemogućavaju, arheološka iskopavanja su zabranjena tamo gde se predpostavlja da se nalaze jevrejski grobovi itd. Vidimo da ovaj period u Izraelu sve više podseća na formiranje strogo teokratske države čija se sudbina nalazi u rukama Agudat Jisrael- a i Šas-a. Šas predstavlja organizaciju koja je slobodno možemo reći proistekla iz Agudat Jisraela i svoj veliki uticaj dostiže osamdesetih godina. Šas se sastoji od Saveta velikih mudraca, upravnika ješivota (škola Talmuda) i hasidskih zajednica poput Elezer Menahem Šah ili Bunem Alter. Sedamdesete godine u Izraelu obeležio je pokret Tešuva ${ }^{4} k o j i ~ s e$ zalagao za strogo poštovanje jevrejskog zakona halaha ${ }^{5}$. Takođe tih godina se javlja još jedan fundamentalistički pokret poznat pod nazivom Guš emunim, ovaj pokret nastaje posle arapskoizrelskog rata i teži rejudeizaciji Izraela i naseljavanju okupiranih oblasti, sa dolaskom

${ }^{4}$ Povratak judaizmu i pokajanje, otuda naziv Pokajnički povratnici odnosno Tešuva
Begina na vlast postaje državno priznat i uz to finansiran iz državne kase. Ovaj pokret brzo deluje stvara jevrejsko podzemlje u okupiranim oblastima i svom silom se bori protiv Arapa. U tim oblastima živi oko 120.000 doseljenika, uglavnom pristalica ovog pokreta. Ovaj pokret se okreće protiv države i pruža otpor izraelskom povlačenju sa poluostrva.

\section{ISLAMSKI FUNDAMENTALIZAM}

Najčešće spominjan verski fundamentalizam je upravo islamski, stoga postoji potreba da se i ovom fundamentalizmu posveti pažnja. Ono što moramo na početku istaći a to je da islamski fundamentalizam nastaje pod uticajem hrišćanskog a kao dokaz možemo na primer uzeti koncept džihada odnosno svetog rata gde jasno vidimo da je taj koncpet identičan krstaškim ratovima u hrišćanstvu a jedina razlika se vezuje za vremensko razdoblje. Džihad je na početku predstavljao samo duhovnu borbu u islamu da bi kasnije prerastao u nešto mnogo opasnije a to je odbrambeno-osvajački rat. Dakle islamski fundamentalisti veruju da se apriori moraju vratiti izvornom islamu jer samo tako može doći do obnove muslimanske moći i njenog daljeg napretka i jačanja u svetu. Uz to što pre mora doći do formiranja, više islamski usmerenih država i naravno društava.Oni svoje tvrdnje baziraju pre svega na istorijskoj potlačenosti, odnosno okupaciji i pre svega nepravdi za koju je naravno kriv niko drugi do taj „nevernički Zapad“, e zbog ovih razloga upravo se oni smatraju dužnima da pod izgovorom obaveza prema Kuranu i islamskom šerijatskom pravu brane svoju religiju jer: "Amerika i njeni saveznici nas masovno ubijaju u Palestini, Čečeniji, Kašmiru i Iraku. Muslimani imaju pravo na odmazdu. Napadi 11. septembra nisu bili usmereni na ženu i decu, prave mete bili su američki simboli vojne $i$ privredne moći. Ono što $S A D$ danas proživljava neznatno je $u$ poređenju sa onim što mi proživljavamo desetinama godina. Naša nacija doživljava poniženje $i$ prezir više od osamdeset godina“(Esposito, 2008). Zato uvek postoji i postojaće taj konflikt između Istoka i Zapada

${ }^{5}$ Halaha predstavlja jevrejski pravni sistem, to je deo Talmuda koji se bavi pravnim odlukama ali i verskim obavezama, međuljudkim odnosima i ritualima. 
odnosno između Islama i Hrišćanstva jer su obe religije izuzetno osetljive na neka nazovimo in imperijalistička nametanja. Istok smatra da je kapitalizam i liberalna demokratija zlo današnjice dok Zapad smatra da se već jednom treba stati na put autoritarnim režimima i vladavini elita - i upravo ova krucijalna razlika stvara sukobe. Nego vratimo se na početak odakle je sve počelo, naime vezivanje fundamentalizma za islam počinje realtivno skoro tačnije od perioda kada je izbila afera 1988. godine oko pisca Salmana Rudžija (Salman Rushdie) koji je optužen za vređanje Poslanika i zahteva iranskog ajatolaha Homeinija (Ruhollah Khomeini) za njegovim ubistvom. Velika Britanija nije prihvatila mešanje nekog tamo ajatolaha u unurašnje stvari države a ponajmanje da prihvati smrtnu kaznu za jednog njenog državljanina. Čitava stvar dobija na značaju jer sada islamski pokreti u drugim zemljama prihvataju ovu problematiku kao svoju. Ovde vidimo jasnu nameru Homeinija da prenese borbu odnosno džihad na međunarodnu lestvicu ali ga je smrt u tome sprečila 1989. godine. Afera Rudži je jasan primer fundamentalizma $u$ islamu jer su antirudžijevski pokreti u evropskim zemljama izazivale i podsticale nasilje a naravno ni Rudžijeva domovina Indija nije ostala netaknuta jer su i tamo izbijali sukobi zbog ove problematike gde je $u$ jednom momentu bilo $i$ mrtvih.

Celokupna ujdurma oko Rudžija nastala je zato što je on u svojoj knjizi napao same fundamente islama oklevetao je nastanak Kurana, Sveto pismo i ličnost Proroka Muhameda znači najveće vrednosti islamske tradicije. E sad da se vratimo malo islamu, dakle islam možda potiče iz VII veka ali se tek u X veku učvršćuje kao versko - politički sistem sa tri oblika:(Kincler, 2002)

1. Predstava o Bogu

2. Tumačenje čovekove suštine

3. Poredak ovostranog - u stanju prividno stabilne ravnoteže

Dakle Bog je jedini uzrok svega što postoji i suštinski razlog sveg zbivanja, musliman je te činjenice uvek i u celosti svestan te je zbog toga njegovo spasenje zagarantovano a islamska država koja je fundirana na izričito božanskom zakonu nameće se kao najidealniji poredak koju je objavio Prorok Muhamed i ostavio u amanet medinskoj zajednici. Nakon Proroka Muhameda
Halif je naslednik koji nosi taj versko politički autoritet u zajednici. I tu se odma javlja problem jer već nakon 30 godina od smrti Proroka Muhameda imamo verovali ili ne tri Halifa gde svaki sebe smatra jedinim legitiminim:

1. Abasidi sa sedištem u Bagdadu

2. Omajadi sa sedištem u Andaluziji

3. Fatamidi sa sedištem u Kairu

Nesposobnost pojedinih da se nametnu kao vlastodršci prisilio in je na formiranje emirata $i$ otvorilo put građanskim ratovima koji su u jednom momentu dovodili do raspada kalifata. Politička kriza koja je dovela do raspada Abasidskog halifata bila je u suštini prožeta duhovnom krizom $\mathrm{u}$ tom momentu $u$ prvi plan iskače sunitiski mislilac Al Mavardi (Abu al-Hasan Ali lbn Muhammad Ibn Habib al-Mawardi) koji se zalaže za vraćanje na stari islamski način života. Ista situacija se javlja kada su Mongoli u XIII veku izvršili upad u halifat gde u prvi plan iskače ovaj put mislilac Ibn Tajmije (Taqi ad-Din Ahmad ibn Taymiyyah) koji se zalaže takođe za vraćanje nepokolobljivom verovanju predaka gde muslimani ne smeju biti zaslepljeni sjajem novina. Možemo zaključiti dakle da u vreme krajnje ugroženosti islamskog sveta fundamentalizam zazuzima svoje mesto $u$ islamu i preispituje one tri temeljne istine o kojim smo pisali. Nego da se vratimo fundamentima islama, kao što znamo pored Kurana, fundamentom islama smatra se tradicija odnosno suna i svakako šerijat odnosno verski zakon koji se poistovećuje sa normativnim pravom društva, politike i države odnosno din va daula - religije i države. Fundamentalizam ovde vezujemo za jasan cilj muslimanskog sveta da se šerijat proglasi jedinim važećim pravom te kao takva religija mora da kontroliše sve segmente društva pa i pravo. Ovu ideju je kasnije najžešće promovisala organizacija poznata pod imenom Muslimansko bratsvo. Možemo dati konačan sud, vidimo iz navedenog teksta da kad govorimo o islamskom fundamentalizmu ne govorimo samo o pravilnom razumevanju i interpretiranju Kurana već i na celokupan šerijat koji je baziran na Kuranu i koji predstavlja konačnu i nepromenljivu Božiju zapovest - ko se toj zapovesti podčini on je pravoverni musliman a ko to ne uradi ni pod tačkom razno ne pripada muslimanskoj zajednici. Kao i u drugim religijama tako i $u$ islamu fundamentalisti mogu biti i pojedinci i grupe. Tipičan primer pojedinaca svakako je bio Moamer 
el Gadafi koji je bio u sukobu sa svima pa i sa svojom muslimanskom braćom jer je samo delove Kurana smatrao fundamentalnim i napisao je svoje Zelene knjige koje smatra važećim i izvan islama. Kad govorimo o fundamentalističkim organizacijama i pokretima nakistaknutiji su svakako: (Khoury, 1989)

1. Al ihvan al muslimun - Muslimanska braća: osnovana od strane Hasana al Bana 1928. godine u Egiptu

2. Džemaati islami - Islamska zajednica: osnovana od strane Al Maududija

3. Al takfir va al hidžra - Anatema i Hidžra: osnovana u Egiptu jedna od najradikalnijih smatraju da ko ne pripada ovoj grupi predstavlja opasnost za islam.

4. Džundn Allah - Božja vojska

5. Al emr bil ma ruf val nehj al munker Neslaganje ispravnog, a zabranjivanje rđavog

6. Tavakuf va tebejun - Postojanost i samouverenje

7. A džemija al šerija - Zakonito društvo

8. Al Kutbijun - Kutbovi sledbenici

9. Milicije pod iranskom kontrolom

\section{ZAKLJUČAK}

$\mathrm{Na}$ osnovu ovog eseja možemo sa apsolutnim pravom potvrditi činjenicu koju je izneo Prof.
Simeunović u svojoj knjizi „Uvod u političku teoriju“ da je fundametalizam jedna vrsta ideologije koja se nameće svom religijskom kolektivu time što se predstavlja kao poslednji spas zajednice koja propada usled odmicanja od pravih i zaboravljenih vrednosti. Zaključili smo da religijski odnosno verski fundamentalizam počiva na subjektivnom pristupu religiji gde je očigledna namera petvaranja religijskog u političko. Takođe jasno je da verski fundamentalizam svoju snagu crpi pre svega iz frustriranih slojeva društva te se najčešće predstavlja kao svojevrsna obnova društvene pravde ali na religijskim principima. Predstavili smo fundamentalističke tendencije u osnovnim religijama poput hrišćanstva, islama i judaizma $\mathrm{i}$ dokazali da je pripisivanje islamu statusa jedine velike religije koja rađa fundamentalizam, ektremizam i nasilje apsolutno nepravedno. Možda se fundamentalizam bori protiv savremenog i modernog ali ih u potpunosti ne odbacuje kao primer uzmimo samo da iranski fundamentalisti svom snagom prihvataju atomsko oružje ili uzmimo sledbenike Bin Ladena kojima je internet osnovno sredstvo zastrašivanja kad sve to sagledamo možemo slobodno reći da se verski fundamentalizam poziva na prošlost ali se i te kako okreće ka budućnosti te stoga mora biti predmet stalne analize ali i kontrole.

\section{CITIRANI RADOVI}

Brasher, B. (2001). „Encyclopedia of Fundamentalism“. New York-London: Routledge,.

Esposito, J. (2008). „Nesveti rat. Teror u ime islama“. Sarajevo: Šahinpašić.

Khoury, A. (1989). „Islamic Fundamentalism“. London: Grafton.

Kincler, K. (2002). „Verski fundamentalizam: hrišćanstvo, judaizam, islam“. Beograd: CLIO.

Munson, H. (2003). "Fundamentalism Ancient \& Modern". Cambridge: Daedalus.

Sandeen, E. ( 1967). "Toward a Historical Interpretation of the Origins of Fundamentalism". Cambridge : Cambridge University Press.

Simeunović, D. (2009). Terorizam. Beograd: Pravni fakultet.

Datum prve prijave:

Datum prijema korigovanog članka:

Datum prihvatanja članka:
08.02.2018.

11.04.2018.

05.09.2018. 
Kako citirati ovaj rad? / How to cite this article?

Style - APA Sixth Edition:

Bursać, B. (2018, 10 15). Verski fundamentalizam. (Z. Čekerevac, Ur.) FBIM Transactions, 6(2), 1-9. doi:10.12709/fbim.06.06.02.01

Style - Chicago Sixteenth Edition:

Bursać, Boris. 2018. „Verski fundamentalizam.“ Urednik Zoran Čekerevac. FBIM Transactions (MESTE) 6 (2): 1-9. doi:10.12709/fbim.06.06.02.01.

Style - GOST Name Sort:

Bursać Boris Verski fundamentalizam [Časopis] // FBIM Transactions / ur. Čekerevac Zoran. Beograd : MESTE, 1510 2018. - 2 : T. 6. - str. 1-9.

Style - Harvard Anglia:

Bursać, B., 2018. Verski fundamentalizam. FBIM Transactions, 15 10, 6(2), pp. 1-9.

Style - ISO 690 Numerical Reference:

Verski fundamentalizam. Bursać, Boris. [ur.] Zoran Čekerevac. 2, Beograd : MESTE, 1510 2018, FBIM Transactions, T. 6, str. 1-9. 